DOI: $10.17805 / z p u .2016 .3 .19$

\title{
Динамика профессиональной идентичности студентов вуза (психологический анализ)
}

\author{
A. -М. АРИАС \\ (САНКТ-ПЕТЕРБУРГСКИЙ АКАДЕМИЧЕСКИЙ УНИВЕРСИТЕТ), \\ E. A. КАРПОВА \\ ( САНКТ-ПЕТЕРБУРГСКИЙ НАЦИОНАЛЬНЫЙ ИССЛЕДОВАТЕЛЬСКИЙ УНИВЕРСИТЕТ \\ ИНФОРМАЦИОННЫХ ТЕХНОЛОГИЙ, МЕХАНИКИ И ОПТИКИ), \\ Т. Г. КУКУЛИТЕ \\ (САНКТ-ПЕТЕРБУРГСКИЙ АКАДЕМИЧЕСКИЙ УНИВЕРСИТЕТ)
}

Статья посвящена анализу динамики изменения профессиональной идентичности студентов вуза. Профессиональная идентичность трактуется как достаточно сложное и неоднозначное понятие, в котором сосредоточены когнитивные, мотивационные и ценностные характеристики, взаимосвязь которых обеспечивает ориентацию в профессиональном выборе и становление личности как компетентного специалиста. Образование в этом процессе занимает одно из ведущих мест. В зависимости от его сроков и содержания оно содействует процессу самоосмысления и самоосуществления личности.

В статье представлены результаты эмпирического исследования, посвященного изучению содержания и структуры профессиональной идентичности студентов вуза первых - пятых курсов. Исследование проведено на базе Санкт-Петербургского академического университета в 2014/2015 учебном году. Теоретической основой исследования выступает концепция о профессиональной идентичности как интегративном понятии.

В качестве показателей профессиональной идентичности студентов рассматриваются уровни профессиональной идентичности - кризис идентичности, мораторий, диффузная идентичность, достигнутая позитивная идентичность, псевдоидентичность. Исследование показало, что становление профессиональной идентичности в период обучения в вузе представляет собой неравномерный процесс, профессиональная идентичность студентов изменяется в зависимости от продолжительности обучения. Так, первый (48,8\%), третий $(51,9 \%)$ и пятый $(39,6 \%)$ курсы сопровождаются ярко выраженным уровнем кризиса профессиональной идентичности. Наиболее стабильными в отношении становления профессиональной идентичности являются второй $(38,8 \%)$ и четвертый $(28,2 \%)$ курсы обучения. Исследование студентов пятого курса показало, что для этой категории наиболее характерна позиция моратория (39,6\%). Диффузный вид идентичности (34,8\%) свидетельствует о том, что возможен кризис профессиональной идентичности в связи с переходом от периода студенчества к профессиональной деятельности.

Ключевые слова: профессиональная идентичность; профессиональное обучение; кризис идентичности; студенты; диффузная идентичность; достигнутая позитивная идентичность; псевдоидентичность

\section{ВВЕАЕНИЕ}

$\Pi$ рофессиональная идентичность представляет собой достаточно сложное и неоднозначное понятие, в котором сосредоточены когнитивные, мотивационные и ценностные характеристики, взаимосвязь которых обеспечивает ориентацию в профессиональном выборе и становление личности как компетентного специалиста. Образование в этом процессе занимает одно из ведущих мест в том смысле, что образование в зависимости от его сроков и содержания содействует 
процессу самоосмысления и самоосуществления личности. Кроме того, образование связано с дифференциацией успеха и потому требует индивидуальной карьерной ориентации. Выявление и раскрытие творческих способностей каждого студента, формирование таких качеств, которые позволят ему занять достойное место в сложной, экономически нестабильной ситуации и, что самое важное, успешно реализовать свой профессиональный потенциал, предопределяют вектор оптимизации его вхождения в профессию.

В исследованиях, посвященных общей проблеме идентичности, можно выделить ряд теоретических подходов, которые составили историю формирования данной проблематики. $\mathrm{K}$ их числу можно по праву отнести психоаналитическое направление (3. Фрейд, Э. Эриксон), символический интеракционизм (Аж. МиА, Ч. Кули, И. Гоффман, Р. Фогельсон), бихевиористический подход (А. Кэмпбелл, М. Шериф), теорию социальной идентичности (Г. Тәшфел, Аж. Тернер), современную феноменологию (П. Бергер, Т. Аукман, А. Шюц).

Значительные результаты в исследовании проблем идентичности были достигнуты и благодаря исследованиям отечественных ученых Н. М. Аксеновой, Е. П. Ермолаевой, А. Б. Шнейдер, Н. А. Ивановой, Е. В. Коневой и других (Аксенова, 2004, Ермолаева, 2008, Шнейдер, 2001 и др.). Результаты этих исследований позволяют создать некоторые представления о закономерностях формирования профессиональной идентичности. Вместе с тем продолжают оставаться актуальными вопросы, связанные с изучением факторов, влияющих на становление профессиональной идентичности.

Цель нашего исследования - изучить содержание и структуру профессиональной идентичности студентов вуза. Аля достижения поставленной цели нами была разработана программа исследования, которая включала анализ литературы по теме профессиональной идентичности, а также эмпирическое исследование.

\section{АНААИЗ ОСОБЕННОСТЕЙ ФОРМИРОВАНИЯ \\ И РАЗВИТИЯ ПОНЯТИЯ ИАЕНТИЧНОСТИ}

Научный интерес к категории «идентичность» формировался в рамках социологии и психологии. Социологический взгляд на проблему идентичности связан прежде всего с именами Ч. Х. Кули и Аж. Мида. Согласно теории Ч. Х. Кули представления индивида о себе в большей степени зависят от восприятия его окружающими. Важную роль такой процесс играет на раннем этапе развития человека, когда именно через восприятия и реакции других людей формируются его идеи и суждения относительно своего «Я» (Кули, 2000).

По мнению Аж. Мида, индивид не только является членом социальной группы и подвергается внешнему давлению, но и сам выступает в качестве субъекта коммуникативной активности и, соответственно, обогащается опытом, который черпает из своего воздействия на других. Согласно Аж. Миду «Я находит выражение либо в самоутверждении, либо в посвящении себя делу сообщества» (Мид, 2009: 173).

Большая заслуга в разработке феномена «идентичность» несомненно принадлежит Э. Эриксону. Определяя идентичность как сложное личностное образование, имеющее многоуровневую структуру, он выделяет три разных смысла данного понятия: бессознательное стремление к непрерывности жизненного опыта, со- 
знательное чувство уникальности индивида, солидарность с идеалами группы (Эриксон, 2006).

Аальнейшее изучение идентичности проходило под влиянием когнитивного подхода. Главная идея исследований в соответствии с этим подходом закдючается в том, что впечатления о мире объединяются в связные интерпретации - идеи, установки, стереотипы, которые выступают в качестве регуляторов социального поведения. А. Тэшфел был одним из первых, кто определил три этапа формирования профессиональной идентичности. Так, на этапе социальной категоризации происходит упорядочивание социального окружения. Этап социальной идентификации связан с тем, что человек помещает себя в ту или иную профессиональную категорию. Этап социальной идентичности позволяет ощутить свое полное социальное отождествление с выбранной группой (Tajfel, 1982).

Вслед за Тэшфелом А. Тернер определяет социальную идентичность как «общую сумму личностных идентификаций, которые являются специфическими социальными категориями, интернализованными в когнитивный компонент Я-концепции» (Tajfel, Turner, 1986: 7).

Анализируя процесс становлением индивидуальности, Аж. Марсиа предположил, что тот или иной вид идентичности проявляется через наблюдаемые паттерны «решения проблем», т. е. актуализируется в ситуации социального выбора. Аж. Марсиа выделил четыре статуса идентичности (диффузная, предрешенная, мораторий, достигнутая), которые могут также выступать и как стадии развития идентичности (Marcia, 1980).

Критерием для выделения статусов служили два параметра: наличие или отсутствие кризиса и принятие обязательств по двум основным сферам функционирования: профессия и ценности. Термин «кризис» относится к периоду жизни человека, когда он размышляет, какой выбрать профессиональный путь развития и каким целям, ценностям необходимо следовать в жизни.

К числу статусов относятся статус достижения идентичности, символизирующий завершение периода поиска, выбора и принятия из нескольких вариантов идентичности наиболее подходящего; статус моратория, предполагающий активный поиск идентичности, сопровождающийся перебором вариантов ее построения; статус предрешенной идентичности, свидетельствующий о готовности субъекта выбрать имеющийся вариант идентичности без поиска дополнительных вариантов; статус диффузной идентичности, сопровождающийся пассивностью субъекта, нежеланием искать, оценивать варианты построения идентичности (там же: 159)

Следует отметить, что из четырех статусов идентичности два свидетельствуют о наличии «устойчивой» личной идентичности (достигнутая и предрешенная идентичность), другие два статуса - о «неустойчивой» идентичности, в большей степени подверженной изменениям в перспективе. Таким образом, Аж. Марсиа разработал статусную модель идентичности, которая представляет собой возможный методологический план для дальнейшего эмпирического изучения личности.

Новым направлением в изучении идентичности является исследование этого феномена в контексте концепций социального капитала (3. Бауман, П. Бурдье, Э. Гидденс, В. А. Ядов). Являясь важным средством воспроизводства общества, социальный капитал выступает одним из факторов преодоления кризиса идентично- 
сти и формирования политики развития. Социальный капитал неразрывно связан и с образованием. Аанное понятие представляется весьма продуктивным для понимания роли и функций образования. А. Коулман показал, что образование в каждом конкретном обществе определяется уровнем уже накопленного социального капитала. Важно подчеркнуть, что основу социального капитала составляет не только принадлежность к определенной группе, но и доверие между членами этой группы (Коулман, 2001).

Анализируя проблему социального капитала, Е. А. Карпова выделяет коммуникативную функцию этого феномена. Обмен информацией и навыками, совместное обсуждение жизненных вопросов - все это делает людей более открытыми и готовыми к инновациям. Как оказалось, именно через контакты люди могут продолжать полученное ранее образование, а также более әффективно предлагать свои услуги на рынке труда (Карпова, 2015).

Включение человека в социальное взаимодействие и порождаемые этим взаимодействием социальные связи и отношения, по мнению В. П. Познякова, совершенно меняют диспозицию. В этом случае классические категории пространства и времени приобретают новый смысл, порождаемый социальностью как атрибутом совместной жизнедеятельности индивидуальных и групповых социальных субъектов (Позняков, 2015).

В отечественных исследованиях показано, что профессиональная идентичность - продукт длительного личностного и профессионального развития. В большей степени эта идея прослеживается в работах Е. П. Ермолаевой. Автор высказывает предположение о том, что профессиональная идентичность формируется только на достаточно высоких уровнях овладения профессией и выступает как устойчивое согласование основных элементов профессионального процесса (см.: Ермолаева, 2008, 2010). Т. Г. Кукулите рассматривает понятие «жизненная стратегия», которое является одним из компонентов, определяющих развитие профессионального самоопределения. Наличие жизненной стратегии личности свидетельствует о социально-психологической зрелости личности, ее способности решать жизненные противоречия, и именно юность, пора студенчества является сенситивными периодом для формирования стратегии жизненного и профессионального самоопределения личности (Кукулите, 2015).

Аналогичного мнения придерживается и Е. Н. Кирьянова, по мнению которой профессиональная идентичность - это вполне устойчивое согласование индивидуальных признаков, условий и содержания профессии, обеспечивающее достижение на конкретном этапе определенного уровня профессионализма, связанного с дальнейшей профессиональной самореализацией (Кирьянова, 1995).

Особую роль идентичности подчеркивает и Н. Н. Федотова, которая предлагает рассматривать идентичность с точки зрения процессуального подхода. Вектор развития самопонимания, солидарности и групповой сплоченности делают возможным коллективное действие. Это превращает идентичность, с одной стороны, в продукт социальной и политической активности и, с другой стороны, в основание последующих действий (Федотова, 2013).

Ряд интересных выводов сделан в работах $\Lambda$. Б. Шнейдер. Так, определяющим фактором становления профессиональной идентичности будущего специалиста, по мнению $\Lambda$. Б. Шнейдер, является информационная среда. Информационная 
среда формирует образы, ценности, статусы и смыслы, наиболее значимые для подростка, в том числе и в сфере будущей профессиональной занятости (Шнейдер, 2001).

Основываясь на концепции Аж. Марсиа, Шнейдер предлагает следующие статусы:

1. Аостигнутая идентичность - статус, сформировавшийся на основе совокупности личностно значимых целей, ценностей и убеждений, переживаемых как личностно значимые.

2. Мораторий - статус кризиса идентичности. Это высокий уровень личностной тревожности, но одновременно и более высокий уровень развития интеллектуальной составляющей.

3. Аиффузная идентичность - статус, Аля которого характерно отсутствие точно сформулированных целей, ценностей и убеждений, а также попыток их формирования.

4. Псевдоидентичность - стабильное отрицание своей уникальности или ее амбициозное подчеркивание в сторону гипертрофированности, сочетающееся с ригидностью Я-концепции.

Нужно заметить, что профессиональная идентичность - это не только осознание своей тождественности с определенной профессиональной общностью. Как правило, человек оценивает эту группу с различных позиций. В разной степени здесь будут присутствовать такие составляющие, как психологическая значимость членства в этой группе, разделяемые профессиональные чувства, своеобразная ментальность, ощущение своей профессиональной компетентности, мотивация самостоятельности и самоэффективности. Континуум этих характеристик дает человеку возможность переживания своей профессиональной целостности и определенности.

Подводя итог обзору имеющихся исследований, подчеркнем, что профессиональная идентификации рассматривается нами как психологическая категория, которая относится к осознанию человеком своей принадлежности к определенной профессии и определенному профессиональному сообществу. По сути, профессиональная идентичность - это аспект интеграции личности и социальной идентичности в профессиональную реальность. Важным аспектом является профессиональное обучение. Благодаря обучению формируются представления о профессиональных нормах и эталонах поведения, уточняются знания о своих ресурсах, начинают работать механизмы профессиональной карьеры, определяется оптимальный индивидуальный стиль. По нашему мнению, именно в этот период происходит формирование и развитие компетенций будущего специалиста.

\section{СОЦИАИЬНО-ПСИХОАОГИЧЕСКОЕ ИССАЕАОВАНИЕ АИНАМИКИ ИЗМЕНЕНИЯ} ПРОФЕССИОНААЬНОЙ ИАЕНТИЧНОСТИ СТУАЕНТОВ В ГУМАНИТАРНОМ ВУЗЕ

Эмпирическое исследование проводилось с октября по май в 2014/2015 учебном году с помощью методики изучения профессиональной идентичности (МИПИ) А. Б. Шнейдер (Шнейдер, 2001), результаты которого дополнялись индивидуальными интервью со студентами и наблюдениями авторов. Выборку составили 92 студента первого - пятого курсов Института гуманитарных и социальных наук Санкт-Петербургского академического университета. Основная гипотеза заклю- 
чалась в том, что становление профессиональной идентичности в период обучения в вузе представляет собой неравномерный процесс, профессиональная идентичность студентов изменяется в зависимости от продолжительности обучения.

Полученные в ходе исследования данные формировались по группам. Аанные представлены в таблице. Аля анализа результатов рассмотрим долю студентов с различным уровнем профессиональной идентичности с первого по пятый год обучения (в \%).

\section{УРОВЕНЬ ПРОФЕССИОНААЬНОЙ ИАЕНТИЧНОСТИ (\%)}

THE LEVEL OF PROFESSIONAL IDENTITY, \%

\begin{tabular}{|l|c|c|c|c|c|}
\hline \multirow{2}{*}{$\begin{array}{c}\text { Уровень профессиональной } \\
\text { идентичности }\end{array}$} & \multicolumn{5}{|c|}{ Годь обучения } \\
\cline { 2 - 6 } & 1 & 2 & 3 & 4 & 5 \\
\hline Кризис идентичности, & & & & \\
мораторий (КИ) & $48,4^{*}$ & $38,8^{*}$ & $51,9 *$ & $28,2 *$ & $39,6^{*}$ \\
Аиффузная идентичность (АИ) & 25,2 & 26,7 & 19,7 & 29,1 & 34,83 \\
Аостигнутая позитивная & & & & & \\
идентичность (АПИ) & 11,3 & 15,9 & 9,8 & 27,3 & 12,44 \\
Псевдоидентичность (ПИ) & 15,1 & 18,6 & 18,6 & 15,4 & 13,2 \\
\hline
\end{tabular}

Примечание: * - различия значимы при $\mathrm{p}<0,05$.

Итак, первый курс - это очень нестабильный этап, связанный прежде всего с осмыслением и адаптацией к новой социальной роли студента. В жизни семнадцатилетнего подростка не происходит такого количества событий, чтобы он мог настаивать на том, что его выбор является достаточно обоснованным. Получение новой информации и размышления о правильности своего выбора способствуют в этот период более успешной адаптации к новой социальной и профессиональной среде. Главное содержание его заключается в формировании студенческой идентификации ( «Я - студент») и прогнозировании будущей профессиональной идентичности. Этот этап в идеале для большинства студентов характеризуется осмыслением профессиональной идентичности.

В нашем случае для студентов первого курса характерен кризис идентичности (48,8\%). Аналогичные результаты получены Н. М. Аксеновой, О. В. Аенисовой, Е. Е. Трандиной, $\Lambda$. М. Федотовой. Так, по результатам исследования О. В. Аенисовой, только половина студентов-медиков имеет достаточно полные представления о будущей профессии (Аенисова, 2008). Конечно, это свидетельствует прежде всего об актуализации проблем, связанных с активным поиском своего места в новом для себя социально-экономическом пространстве. Выход за пределы зоны комфорта, как правило, сопровождается достаточно высоким уровнем тревожности. Аргументацией таких результатов может служить предположение о том, что студенты первого курса только приступили к обучению в вузе и, следовательно, у них еще не сформировалось позитивное представление о будущей профессии. Одной из причин сложившейся ситуации может быть отсутствие достаточной ин- 
формационной составляющей, связанной с профессиональной деятельностью. Как известно, на первом курсе запланировано не так много дисциплин, помогающих понять основы будущей профессии. Аополняют эту картину результаты интервью, проведенного со студентами нашего вуза, которые также подтверждают выявленный кризис. Больше половины студентов первого курса, а именно 53\%, имеют весьма отвлеченные представления о характере профессии, которую они выбрали. Отсутствует и понимание того, какие компетенции следует развивать, чтобы успешно интегрироваться в предполагаемую профессиональную среду.

Вызывает некоторое беспокойство диффузная идентичность - четверть студентов $(25,2 \%)$ демонстрируют отсутствие конкретного целеполагания будущего развития. При этом пассивность демонстрируется и по отношению к групповой сплоченности. При отсутствии достаточного понимания идентичности люди переживают такие негативные состояния, как пессимизм, апатия, отчуждение, тревога и безнадежность. Только 11,3\% достаточно отчетливо представляют свою будущую профессиональную деятельность и в соответствии с осуществленным выбором планируют развивать свою карьерную траекторию. Осознание предстоящих трудностей в обучении не уменьшает стремления придерживаться избранного направления.

Что же происходит дальше? Второй курс - это период, когда происходит практически полная адаптация к требованиям новой социально-профессиональной роли, происходит понимание своего потенциала, осознание успеха, которого можно достичь благодаря собственным усилиям. Общая картина показателей профессиональной идентичности второго курса существенным образом меняется. Несмотря на то что по-прежнему кризис идентичности продолжает «лидировать» $(37,1 \%)$, его показатели имеют некоторую тенденцию к снижению. Практически не меняется показатель диффузной идентичности - 26,7\% против 25,2 на первом курсе. Значение позитивной идентичности несколько увеличивается до 15,9\%. Это говорит о том, что некоторая часть студентов первого курса $(57,1 \%)$ прошла период кризиса и сформировала континуум личностно-значимых целей, профессиональных интересов и стратегий. Снижение показателей идентичности зафиксировано и в исследовании Е. Е. Трандиной, в котором принимали участие студенты юридического факультета. Автор высказывает предположение о том, что это явление связано с так называемым адаптационном кризисом (Трандина, 2006).

Считается, что на третьем курсе конструктивные схемы социализации и саморазвития находятся в достаточно стабильном состоянии. Однако в нашем случае анализ результатов показал иную картину. Студенты третьего курса обозначили признаки увеличения кризиса идентичности (51,9\%). Возврат на исходные позиции объясняется многими причинами, среди которых отсутствие четкого понимания места и роли изучаемых предметов, их профессиональной значимости, слабое понимание применения полученных знаний в будущей профессиональной деятельности. Несмотря на достаточно стабильную траекторию развития профессиональной идентичности студентов, продемонстрированную в исследовании Н. М. Аксеновой, невозможно не согласиться с некоторыми выводами, сделанными в этой работе. Так, например, автору удалось подтвердить взаимосвязь между продуктивностью и осмысленностью предыдущего опыта и перспективной направленностью на профессиональную деятельность. Более ранние сроки реализа- 
ции своих профессиональных планов придают большую заинтересованность профессией (Аксенова, 2004). Отсутствие достижений приводит к потере интереса к будущей профессии. Наша интерпретация этого явления объясняется также усилением кризиса экономических и общественных факторов, с которыми сталкиваются студенты гуманитарного направления во время своей практики на третьем курсе. Вместе с тем на этом фоне абсолютно не меняются показатели псевдоидентичности.

Вызывает некоторую озабоченность тот факт, что практически почти в два раза упала достигнутая позитивная идентичность, набравшая только 9,8\%. Аиффузный вид идентичности, присущий студентам третьего курса, свидетельствует о том, что сформированные ранее цели в настоящий момент стали недостижимыми или потеряли свою актуальность. Сравнивая себя с другими, личность сталкивается с противоречиями и неопределенностями. В этот момент нарастает неблагоприятный эмоциональный фон, студенты переживают целый набор негативных психических состояний. Эти причины можно устранить, если улучшить проектирование учебного процесса: в большей степени акцентировать внимание на практико-ориентированном обучении, использовать методы обучения, имеющие высокий позитивный отклик у студентов. Это и требующий интеллектуального напряжения метод проектов, и профессионально-ориентированные деловые игры, различные кейсы и т. А.

Как правило, для студентов четвертого курса характерны первые попытки практической реализации своих знаний и навыков, которые они совершают в различных вариантах. Очередной виток социализации, развитие нового ролевого репертуара позволяют наметить оптимальные перспективы своей интеграции в желаемое сообщество профессионалов. Происходит новое осмысление профессиональной занятости, принадлежности к определенной профессиональной группе, конкретизация вариантов творческой самореализации. И с одной стороны, әто дает свои позитивные результаты - увеличивается позитивная идентичность $(27,3 \%)$.

Можно сказать, что в сознании современных студентов происходит формирование идеологии продуктивизма, когда нужно вкладывать силы в то, что продуктивно, эффективно, то, что является ресурсом для данного общества. Но вместе с тем увеличивается и диффузная идентичность - 29,1\%. Важно отметить значительное снижение показателя моратория, это достаточно ярко показывает стремление студентов четвертого курса преодолеть кризис и выбрать альтернативные варианты своего профессионального развития.

Ну и наконец, редкая возможность оценить состояние будущих специалистов пятого курса. Этот период условно можно назвать уточняющим. Исследование студентов пятого курса показало, что для этой категории наиболее характерна позиция моратория (39,6\%). Аиффузный вид идентичности $(34,8 \%)$ свидетельствует о том, что возможен кризис профессиональной идентичности в связи с переходом от периода студенчества к профессиональной деятельности. Аругие виды идентичности находятся на более низком уровне, из них выделяется достигнутая позитивная идентичность, набравшая только 12,4\% по шкале идентичности. Эти показатели практически в два раза меньше, чем показатели $\Lambda$. М. Федотовой. В исследовании данного автора прослеживается явная тенденция к нарастанию профессиональной идентичности от первого к пятому курсу. Автор акцентирует 
внимание на том, что вуз создает одинаковые условия для развития профессиональной идентичности, и к пятому курсу $68 \%$ выпускников обретают высокий уровень и только $32 \%$ - низкий уровень развития профессиональной идентичности студентов (Федотова, 2011).

Особый интерес в этой связи вызывают общие выводы Е. Е. Трандиной, которые частично близки нашим данным. Так, автору удалось определить, что наиболее сильное и устойчивое влияние на становление профессиональной идентичности оказывает мотивационный компонент (Трандина, 2006). Связь между всеми компонентами обнаруживается только на первом курсе, на остальных курсах они практически не связаны между собой. Минимальный уровень развития демонстрирует когнитивный компонент. Кроме этого, в работе автора прослеживается такая идея, что формирование собственно профессиональной идентичности происходит после окончания профессионального заведения, а именно в период самостоятельной работы.

С помощью статистических методов (угловое преобразование Фишера) доказано, что на первом, третьем и пятом годах обучения доля студентов, переживающих кризис, выше, чем доля студентов с другими уровнями идентичности $(\mathrm{p}<0,05)$. Это дает нам возможность утверждать, что первый, третий и пятый годы обучения являются наиболее сложными для профессионального становления студентов. Преобладание студентов с кризисом профессиональной идентичности объясняется не только недостаточной ориентацией программ обучения на профессионализацию, нежеланием работодателей проявлять больший интерес к молодым специалистам, но и слабой информационной активностью самих студентов.

Переживание кризиса студентами первого курса логически объясняется тем, что на первом курсе студент только начинает приобщаться к миру выбранной профессии, он не обладает необходимыми знаниями, имеет мозаичные представления о выбранной специальности.

Более того, наблюдения за поведением студентов первого курса на практических занятиях позволили преподавателям СПбАУ высказать мнение о том, что большая часть респондентов (более 52\%) на начальном этапе обучения имеют весьма слабые представления о характере своей будущей профессиональной деятельности, что также может влиять на переживание кризиса в этот период.

Следующий этап, а именно обучение на втором курсе, в меньшей степени негативно сказывается на формировании профессиональной идентичности. На втором курсе это может быть связано с успешным усвоением различных предметов и принятием своей будущей профессии. Второй курс характеризуется большей вовлеченностью студентов в общественную жизнь университета. Активно развиваются социальные контакты, позволяющие создавать группы по интересам. Позитивный настрой, новые впечатления преобразуют слабо связанные представления в некую целостную систему, благодаря которой студенты с удовольствием воспринимают новую информацию о будущей профессии, улучшая показатели обучения. На третьем курсе уже получен необходимый объем знаний для того, чтобы сформировать более точную картину своей будущей специальности. Многие студенты получили направления на профессиональную практику в конце второго курса. Но часто именно в этот период приходит разочарование, студент понимает, что его ожидания не соответствуют реальной действительности. Во время обучения на 
четвертом курсе приходит время определяться в жизни и строить собственные профессиональные планы. Однако недостаточно высокие показатели свидетельствуют о слабом понимании своего предназначения. Кризис профессиональной идентичности студентов пятого курса чаще всего возникает в связи с изменением ролевой позиции и озабоченностью профессиональной занятостью.

\section{ЗАКАЮЧЕНИЕ}

В ходе проведенного эмпирического исследования нами были выявлены особенности профессиональной идентичности. Как и предполагалось, на протяжении всего процесса обучения студентов в высшем учебном заведении зафиксированы изменения общего фона профессиональной идентичности. Эти изменения имели место и в исследованиях других авторов. Уровень профессиональной идентичности студентов неравномерно меняется от первого к пятому году обучения. Первый, третий и пятый курсы сопровождаются ярко выраженным кризисом профессиональной идентичности. Наиболее стабильными в отношении становления профессиональной идентичности являются второй и четвертый курсы обучения.

Профессиональная идентичность студентов в процессе обучения практически не достигает своего оптимального уровня. В этом случае мы сталкиваемся с очевидной проблемой соответствия существующей системы психолого-педагогических условий, направленных на формирование профессионального самосознания молодых специалистов современным условиям трудовой деятельности. Кардинальное изменение психолого-педагогических условий преобразует и механизмы формирования профессиональной идентичности. Концентрация внимания на информационно-познавательном аспекте относительно профессиональной самореализации может способствовать развитию интереса к самостоятельному поиску профессиональных групп и сообществ. В любом контексте это открывает широкие возможности для социального взаимодействия, для оценки себя с точки зрения других, большей ответственности за качественное формирование своих профессиональных знаний и навыков.

Входя в новые сферы жизни, пытаясь примкнуть к новой группе, человек всегда испытывает кризисы идентичности. Успешная интеграция в этом случае будет завесить не только от активной позиции студента, но и от целенаправленной деятельности вуза в организации различного рода мероприятий, связанных с будущей профессиональной деятельностью студентов.

\section{СПИСОК АИТЕРАТУРЫ}

Аксенова, Н. М. (2004) Аичностные характеристики эго-идентичности как фактор профессионального самоопределения студентов в вузе : дис. ... канд. психол. наук. Кемерово. $137 \mathrm{c.}$

Аенисова, О. В. (2008) Становление профессиональной идентичности студента-медика в образовательном процессе вуза : дис. ... канд. психол. наук. Уфа. 218 с.

Ермолаева, Е. П. (2008) Психология социальной реализации профессионала. М. : ИзА-во Института психологии РАН. 347 с.

Ермолаева, Е. П. (2010) Принцип превентивной оценки профессиональной идентичности специалистов в процессе обучения и переподготовки // Вестник Нижегородского университета им. Н. И. Аобачевского. № 1. С. 33-36. 
Карпова, Е. А. (2015) Социальный капитал личности в перспективе развития гуманитарного образования // Инновационная наука. № 3. С. 131-133.

Кирьянова, Е. Н. (1995) Психология формирования личности профессионала // Психологический журнал. Т. 16. № 4. С. 26-34.

Коулман, Аж. (2001) Капитал социальный и человеческий // Общественные науки и современность. № 3. С. 122-139.

Кукулите, Т. Г. (2015) Проблема жизненного самоопределения в психологии // Роль интеллектуального капитала в экономической, социальной и правовой культуре XXI века : сб. науч. тр. участников Междунар. науч.-практ. конференции / отв. ред. Г. А. Костин, Г. В. Гетманова, И. А. Усова. СПб : Санкт-Петербургский университет управления и экономики. 554 с. С. 190-194.

Кули, Ч. Х. (2000) Человеческая природа и социальный порядок : пер. с англ. М. : ИдеяПресс ; Аом интеллектуальной книги. 320 с.

Мид, Аж. (2009) «І» и «Ме»как фазы Я // Мид Аж. Избранное : сб. переводов / сост. и переводчик В. Г. Николаев ; отв. ред. А. В. Ефременко. М. : ИНИОН РАН. 290 с. C. $170-177$.

Позняков, В. П. (2015) Концепция психологических отношений человека: пространственный и временной аспекты // Знание. Понимание. Умение. № 3. C. 228-238. DOI: 10.17805/zpu.2015.3.19

Трандина, Е. Е. (2006) Становление профессиональной идентичности у студентов юридического вуза : дис. ... канд. психол. наук. Ярославль. 225 с.

Федотова, А. М. (2011) Формирование профессиональной идентичности студентов в процессе обучения в вузе: дис. ... канд. пед. наук. Кемерово. 272 с.

Федотова, Н. Н. (2013) Концепции идентичности в условиях нелинейной социокультурной динамики // Знание. Понимание. Умение. № 2. С. 52-62.

Шнейдер, А. Б. (2001) Профессиональная идентичность. М. : МОСУ. 256 с.

Эриксон Э. (2006) Идентичность: юность и кризис : пер. с англ. М. : Флинта ; МПСИ ; Прогресс. 342 с.

Marcia, J. E. (1980) Identity in adolescence // Adelson J. (ed.) Handbook of adolescent psychology. N. Y. : John Wiley. 845 p. P. 159-187.

Tajfel, H. (1982) Instrumentality, identity and social comparisons // H. Tajfel (ed.). Social identity and intergroup relations. Cambridge University Press. 546 p. P. 483-505.

Tajfel, H., Turner, J. C. (1986) The social identity theory of inter-group behavior // S. Worchel, L. W. Austin (eds.). Psychology of Intergroup Relations. Chigago: Nelson-Hall. 369 p. P. 7-24.

Аата поступления:13.04.2016 г.

\section{DYNAMICS OF PROFESSIONAL IDENTITY IN HIGHER SCHOOL STUDENTS (PSYCHOLOGICAL ANALYSIS) \\ A. -M. ARIAS \\ (SaINT Petersburg ACAdemic University), \\ E. A. KARPOVA \\ (Saint Petersburg National Research University of Information Technologies, MECHANICS AND OPTICS), \\ T. G. KUKULITE \\ (SaINT Petersburg ACADEMIC UnIVERSITY)}

The article examines the dynamics of change in professional identity of the university students. Professional identity is a rather complex and ambiguous concept which focuses on cog- 
nitive, motivational and value characteristics. Their correlation helps an individual self-determine as a professional and develop the necessary competences. One of the leading roles in this process belongs to education: in accordance with its duration and content, education contributes to an individual's self-actualization and self-fulfilment.

The article presents the outcomes of empirical research into the content and structure of professional identity in university students from freshmen to seniors (St. Petersburg Academic University, 2014/2015). We view professional identity as an integrative concept which reflects the complex interrelation of a number of personal characteristics, determines one's choice of occupation, foresee the consequences of this choice and fully develop one's professional abilities.

Several levels of professional identity - identity crisis, moratorium, diffuse identity, achieved positive identity, pseudo-identity - act as indicators of students' professional identity. Our study has shown that the rise of professional identity at university is an uneven process which depends on the duration of training. At their first $(48.8 \%)$, third $(51.9 \%)$ and fifth $(39.6 \%)$ year at university students exhibit a conspicuous identity crisis, while the second $(38.8 \%)$ and fourth $(28.2 \%)$ years display stable professional identity. 5 th year seniors were found to be most inclined to assume the moratorium position. Diffuse identity $(34.8 \%)$ proves that a professional identity crisis is possible during the transfer from study to work.

Keywords: professional identity; vocational training; social identification; identity crisis; diffuse identity; achieved positive identity; pseudo-identity

\section{REFERENCES}

Aksenova, N. M. (2004) Lichnostnye kharakteristiki ego-identichnosti kak faktor professional'nogo samoopredeleniia studentov $v$ vuze : Dissertation ... Candidate of Psychology. Kemerovo. 137 p. (In Russ.).

Denisova, O. V. (2008) Stanovlenie professional'noi identicbnosti studenta-medika $v$ obrazovatel' nom protsesse vuza : Dissertation. ... Candidate of Psychology. Ufa. 218 p. (In Russ.).

Ermolaeva, E. P. (2008) Psikbologiia sotsial' noi realizatsii professionala. Moscow, Izd-vo Instituta psikhologii RAN. 347 p. (In Russ.).

Ermolaeva, E. P. (2010) Printsip preventivnoi otsenki professional'noi identichnosti spetsialistov v protsesse obucheniia i perepodgotovki. Vestnik Nizhegorodskogo universiteta im. N. I. Lobachevskogo, no. 1, pp. 33-36. (In Russ.).

Karpova, E. A. (2015) Sotsial'nyi kapital lichnosti v perspektive razvitiia gumanitarnogo obrazovaniia. Innovatsionnaia nauka, no. 3, pp. 131-133. (In Russ.).

Kir'ianova, E. N. (1995) Psikhologiia formirovaniia lichnosti professional. Psikbologicheskii zhurnal, vol. 16, no. 4, pp. 26-34. (In Russ.).

Coleman, J. (2001) Kapital sotsial'nyi i chelovecheskii. Obshchestvennye nauki i sovremennost', no. 3, pp. 122-139. (In Russ.).

Kukulite, T. G. (2015) Problema zhiznennogo samoopredeleniia v psikhologii. In: Rol' intellektual' nogo kapitala v ekonomicheskoi, sotsial' noi i pravovoi kul' ture XXI veka: sb. nauch. tr. uchastnikov Mezhdunar. nauch.-prakt. konferentsii, ed. G. A. Kostin, G. V. Getmanova and I. A. Usova. St. Petersburg, Sankt-Peterburgskii universitet upravleniia i ekonomiki. 554 p. Pp. 190-194. (In Russ.).

Cooley, Ch. H. (2000) Chelovecheskaia priroda i sotsial'nyi poriadok,. Moscow, IdeiaPress, Dom intellektual'noi knigi. 320 p. (In Russ.).

Mead, G. H. (2009) «I» i «Me» kak fazy Ia. In: Mead, G. H. Izbrannoe : sbornik perevodov, comp. and trasl. V. G. Nikolaev, ed. D. V. Efremenko. Moscow, INION RAN. 290 p. Pp. 170-177. (In Russ.). 
Pozniakov, V. P. (2015) Kontseptsiia psikhologicheskikh otnoshenii cheloveka: prostranstvennyi i vremennoi aspekty. Znanie. Ponimanie. Umenie, no. 3, pp. 228-238. DOI: 10.17805/ zpu.2015.3.19 (In Russ.).

Trandina, E. E. (2006) Stanovlenie professional' noi identichnosti u studentov iuridicheskogo vuza: Dissertation... Candidate of Psychology. Yaroslavl'. 225 p. (In Russ.).

Fedotova, L. M. (2011) Formirovanie professional' noi identichnosti studentov $v$ protsesse obucheniia v vuze: Dissertation... Candidate of Pedagogy. Kemerovo. 272 p. (In Russ.).

Fedotova, N. N. (2013) Kontseptsii identichnosti v usloviiakh nelineinoi sotsiokul'turnoi dinamiki. Znanie. Ponimanie. Umenie, no. 2, pp. 52-62. (In Russ.).

Shneider, L. B. (2001) Professional' naia identichnost'. Moscow, MOSU. 256 p. (In Russ.).

Erikson, E. (2006) Identicbnost' : iunost' i krizis, transl. by English. Moscow, Flinta; MPSI; Progress. 342 p. (In Russ.).

Marcia, J. E. (1980) Identity in adolescence. In: Adelson J. (ed.) Handbook of adolescent psychology. N. Y., John Wiley. 845 p. Pp. 159-187.

Tajfel, H. (1982) Instrumentality, identity and social comparisons. In: H. Tajfel (ed.). Social identity and intergroup relations. Cambridge University Press. 546 p. Pp. 483-505.

Tajfel, H. and Turner, J. C. (1986) The social identity theory of inter-group behavior. In: S. Worchel, L. W. Austin (eds.). Psychology of Intergroup Relations. Chigago: Nelson-Hall. 369 p. Pp. 7-24.

Submission date: 13.04.2016.

Ариас Анна-Мария - кандидат филологических наук, доцент кафедры педагогики, психологии и переводоведения Санкт-Петербургского академического университета. Адрес: 190103, Россия, г. Санкт-Петербург, Аермонтовский пр., А. 44, лит. А. Тел.: +7 (812) 575-11-19. Эл. адрес: anmar-74@mail.ru

Карпова Елена Алексеевна - кандидат психологических наук, доцент кафедры управления и права Санкт-Петербургского национального исследовательского университета информационных технологий, механики и оптики. Адрес: 196135, Россия, г. Санкт-Петербург, ул. Гастелло, д. 12. Тел.+7 (812) 371-81-19. Эл. адрес: dr.karpova@mail.ru

Кукулите Татьяна Геннадьевна - кандидат психологических наук, доцент кафедры педагогики, психологии и переводоведения Санкт-Петербургского академического университета. Адрес: 190103, Россия, г. Санкт-Петербург, Аермонтовский пр., А. 44, лит. А. Tел.: +7 (812) 575-11-19. Эл. aspec: kukulitetg@mail.ru

Arias Anna-Maria, Candidate of Philology, Associate Professor, Department of Pedagogy, pPsychology and Theory of Translation, Saint Petersburg Academic University. Postal address: Lit. A, 44 Lermontov Ave., 190103 St. Petersburg, Russian Federation. Tel.: +7 (812) 575-11-19. E-mail: anmar-74@mail.ru

Karpova Elena Alekseyevna, Candidate of Psychology, Associate Professor, Department of Management and Law, Saint Petersburg National Research University of Information Technologies, Mechanics and Optics. Postal address: 12 Gastello St., 196135 St. Petersburg, Russian Federation. Tel.: +7 (812) 371-81-19. E-mail: dr.karpova@mail.ru

Kukulite Tatiana Gennadievna, Candidate of Psychology, Associate Professor, Department of Pedagogy, Psychology and Theory of Translation, Saint Petersburg Academic University. Postal address: Lit. A, 44 Lermontov Ave., 190103 St. Petersburg, Russian Federation. Tel.: +7 (812) 575-11-19. E-mail: kukulitetg@mail.ru 